\title{
Use of Traditional East Asian Medicine to Diagnose and Kampo Medicine Kamishoyosan to Treat Survivors of the Great East Japan Earthquake 2011: A Retrospective Study
}

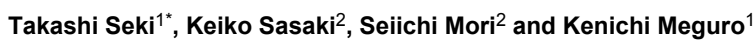 \\ ${ }^{1}$ Division of Geriatric Behavioral Neurology, Tohoku University CYRIC, 6-3 Aoba, Aramaki, Aoba-ku, Sendai, Miyagi 980-8578, Japan \\ 2Urayasu special elderly nursing home, 86-5 Shimoyoden aza Kasima, Natori, Miyagi 981-1223, Japan
}

"Corresponding author: Takashi Seki, Division of Geriatric Behavioral Neurology, Tohoku University CYRIC, 6-3 Aoba, Aramaki, Aoba-ku, Sendai 980-8578, Japan, Tel: +81-22-795-7800; E-mail: tseki.tohoku@gmail.com

Rec date: Aug 12, 2014, Acc date: Sep 19, 2014, Pub date: Sep 21, 2014

Copyright: (c) 2014 Seki T, et al. This is an open-access article distributed under the terms of the Creative Commons Attribution License, which permits unrestricted use, distribution, and reproduction in any medium, provided the original author and source are credited

\begin{abstract}
Objective: In the aftermath of the Great East Japan Earthquake of March 11, 2011 and the associated tsunami, the Japanese medical system was not adequately prepared to deal with the many cases of post-traumatic stress disorder (PTSD), and commonly used pharmaceuticals were not always effective in dealing with the symptoms of PTSD. The aim of this paper is to evaluate the physical and mental condition of tsunami survivors by using traditional East Asian medicine (TEAM) principles and examine the effects of Kampo medicine (Japanese herbal medicine) Kamishoyosan (Jia-wei-xiao-yao-san) on stress-related disorders such as PTSD.

Method: The study participants consisted of 32 tsunami survivors of the Great East Japan Earthquake. Clinical records were used to analyze (1) patient complaints, (2) diagnosis, and (3) treatment with traditional Chinese medicine. The clinical records were also used for Japanese-language version of the Impact of Event Scale Revised (IES-R-J) assessments.

Results: Thirty-two employees at the Urayasu nursing facility (7 men, 25 women; age, $40 \pm 13$ years) were enrolled as patients. The physical symptoms reported by the patients were insomnia, fatigue, palpitations, and shoulder discomfort; the mental symptoms included anxiety, sense of guilt, dreams, fear, anger, and irritation. Among TEAM syndromes, "liver qi stagnation" and "depressed liver qi transforming into fire" were most common. The herbal medicine Kamishoyosan was prescribed for 23 participants. The IES-R-J scores after the prescribed use of Kamishoyosan showed significant improvement compared to the pre-treatment IES-R-J scores.

Conclusions: Kamishoyosan for applicable cases can be helpful as an adjunctive therapy for treatment of stressrelated disorders such as PTSD following major disasters. Further investigation of the role of Kamishoyosan in reducing the symptoms of PTSD is warranted. Follow-up for survivors and rescue workers affected by the Great East Japan Earthquake is indispensable.
\end{abstract}

Keywords: Post-Traumatic Stress Disorder (PTSD); Herbal medicine; Kamishoyosan; IES-R; the Great East Japan Earthquake

\section{Introduction}

The Great East Japan Earthquake of March 11, 2011 was the fourth earthquake of its size in the world since 1900 [1] and there are many reports of post-traumatic stress disorder (PTSD) associated with it [2]. PTSD is more common than previously thought [3]; for example, 4 years after tsunami caused by the Hokkaido Nanseioki Earthquake, $16.7 \%$ of survivors reported that their life remained unsettled [4].

A total of 15,887 persons are known to have died in the Great East Japan Earthquake and the number of people still missing was 2,615 as of July 10, 2014 [5]. The number of refugees and evacuated persons living in temporary housing was 251,419 as of June 12, 2014 [6]. Of the 1,006 victims of the disaster living in the stricken areas of Iwate, Miyagi, and Fukushima prefectures, 59\% reported that reconstruction had not been taking place, $53 \%$ said that the reason for the lack of reconstruction was that the location of their future residence had not yet been decided, and $24 \%$ said that they did not want to return to where they lived before the tsunami. The most common reason given for not returning to their previous home was anxiety about the tsunami [7]. Rescue workers, as well as survivors, are at risk for developing mental disorders $[8,9]$.

Our institution and nursing facility-Tohoku University and the Urayasu special elderly nursing home-were located at the center of disaster area; there were varying responses to the tragic disaster [10-12].

One of the observations that became apparent after the earthquake was that commonly used pharmaceuticals were not always effective and often proved unsatisfactory for patients. For example, the drugs commonly used to treat PTSD were known to have side effects and could pose risks for some people [13-15]. There was also insufficient evidence to recommend Complementary and Alternative Medicine (CAM) approaches, including traditional medicine, as first-line treatments for PTSD. Nevertheless, herbal medicines have been in common use for mental care in traditional East Asian medicine 
Citation: Seki T, Sasaki K, Mori S, Meguro K (2014) Use of Traditional East Asian Medicine to Diagnose and Kampo Medicine Kamishoyosan to Treat Survivors of the Great East Japan Earthquake 2011: A Retrospective Study. Altern Integr Med 3: 172. doi: $10.4172 / 2327-5162.1000172$

Page 2 of 7

(TEAM) from ancient times [16]. Kampo medicine Kamishoyosan (Jia-wei-xiao-yao-san) is an example of one such Japanese herbal medicine currently in use [17-23]. After the Sichuan earthquake in China in 2008, Xiao-Tan-Jie-Yu-Fang, which was developed from Jiawei-xiao-yao-san (Kamishoyosan), was used for patients with PTSD [24]. We used TEAM to treat the survivors of the Great East Japan Earthquake in 2011; 72\% of patients, for whom Kamishoyosan was indicated by TEAM syndromes, were prescribed Kamishoyosan. The IES-R-J scores obtained before and after treatment were analyzed based on the medical records.

\section{Materials and Methods}

\section{Study design and participants}

This retrospective study was conducted in Natori City, which is located near the center of the tsunami disaster area associated with the Great East Japan Earthquake in 2011 (Figure 1). The study participants were surviving employees of the Urayasu nursing home facility, which was destroyed by the tsunami.

After the tsunami disaster, the authors visited the survivors and treated them in the facility to which they had been taken. All the patients were suffering from stress-related disorders such as PTSD. They were diagnosed according to the theories of TEAM and prescribed herbal medicines. To evaluate the effects of the herbal medicines on the patients, IES-R-J assessments were performed before and after prescription of the medicines.

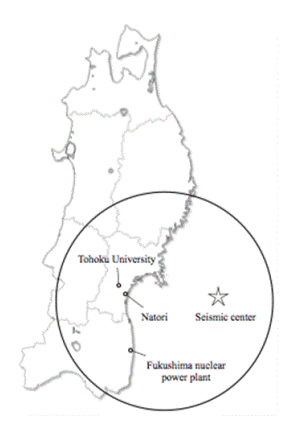

Figure 1: Location of Natori city

\section{Outcome Measures}

Assessments of the damage to the patients caused by the earthquake and tsunami were carried out in three stages: (1) identifying chief complaints reported at the first examination, which took place 1 to 2 months after the disaster, (2) performing diagnosis according to TEAM theories, and (3) assessing medical records with the Japaneselanguage version of the Impact of Event Scale - Revised (IES-R-J) [25]. All three stages were performed using the patient's clinical records. Most of the patients completed the IES-R-J twice, as requested-before and after receiving the prescription. The IES-R-J assessments were analyzed only in patients for whom Kamishoyosan was indicated by TEAM syndromes such as "liver qi stagnation" or "depressed liver qi transforming into fire."

The IES-R-J is a short, self-reporting questionnaire with 22 questions, 5 of which were added to the original Horowitz (IES) [26] to better capture the DSM-IV (Diagnostic and Statistical Manual of
Mental Disorders) criteria for PTSD [27]. This tool is an appropriate instrument to measure the subjective response to a specific traumatic event in the senior population, especially in the response sets of intrusion (intrusive thoughts, nightmares, intrusive feelings and imagery, dissociative-like re-experiencing), avoidance (numbing of responsiveness, avoidance of feelings, situations, and ideas), and hyperarousal (anger, irritability, hypervigilance, difficulty concentrating, heightened startle), as well as to produce a total subjective stress IES-R-J score.

\section{Preparation of herbal medicine Kamishoyosan (Jia-wei-xiao- yao-san) and dispensing of the medicine}

Kamishoyosan extract is an over-the-counter (OTC) drug that was supplied for prescription to the patients by Kotaro Pharmaceutical Co., Ltd (Osaka, Japan). Kamishoyosan extract is produced by Kotaro Pharmaceutical Co., Ltd. It contains 10 herbs in the following quantities: Bupleuri Radix (1.5g), Angelicae Radix (1.5g), Poria (1.5g), Atractylodis Rhizoma (1.5g), Paeoniae Radix (1.5g), Menthae Herba (0.5g), Glycyrrhizae Radix (1.0g), Zingiberis Rhizoma (0.5g), Moutan Cortex (1.0g), and Gardeniae Fructus (1.0g). These herbs are registered in the Pharmacopoeia of Japan, 15th version. Patients who participated in the study and were approved to receive the Kamishoyosan prescription as the result of having one or more TEAM syndromes received 3 tablets of Kamishoyosan $(0.75 \mathrm{~g}$ extract $) 3$ times a day. The processes involved in the production and distribution of Kamishoyosan, in compliance with Good Manufacturing Practices for Kampo products, have also been approved by the Ministry of Health, Labor, and Welfare of Japan.

\section{Statistical Analysis}

Scores for the IES-R-J obtained before and after the prescription of Kamishoyosan were compared using paired t-test. The statistical analysis software used was JMP Pro version 11.0 (SAS Institute Inc., Cary, NC, USA). Significance levels were defined as $\mathrm{p}<0.05$.

\section{Results}

\section{Participants}

A total of 32 employees ( 7 men and 25 women; age, $40 \pm 13$ years) at the Urayasu nursing home facility were enrolled as patients in the research project.

\section{The damage situation for the study patients}

The Urayasu nursing facility was completely destroyed by the tsunami. Forty-three of the 163 elderly residents died, along with 4 of the 62 employees. Of the 32 employees enrolled as patients in the study, 31 witnessed the death of one or more residents, or experienced a crisis in their own life. The families of 2 patients died in the disaster and the families of 2 other patients disappeared; 4 patients had their houses completely destroyed, and the houses of 2 other patients were partially destroyed. The cars of 14 patients were carried away by the tsunami.

\section{Chief complaints of patients at the first examination}

Figure 2a shows the physical symptoms and Figure $2 \mathrm{~b}$ shows the mental symptoms at the first examination. Among physical symptoms, insomnia, fatigue, palpitations, and shoulder discomfort were most 
Citation: Seki T, Sasaki K, Mori S, Meguro K (2014) Use of Traditional East Asian Medicine to Diagnose and Kampo Medicine Kamishoyosan to Treat Survivors of the Great East Japan Earthquake 2011: A Retrospective Study. Altern Integr Med 3: 172. doi: $10.4172 / 2327-5162.1000172$

Page 3 of 7

prevalent, while anxiety, sense of guilt, dreams, fear, anger, and irritation were the most common mental symptoms. The reasons given by the patients for their anxiety were vague, relating to aftershocks, the tsunami, uncertainty about their future, and lack of employment.

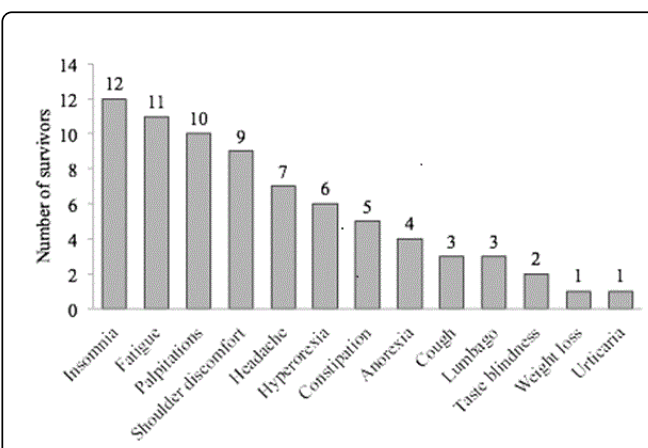

Figure 2A: Symptoms at first medical examination.

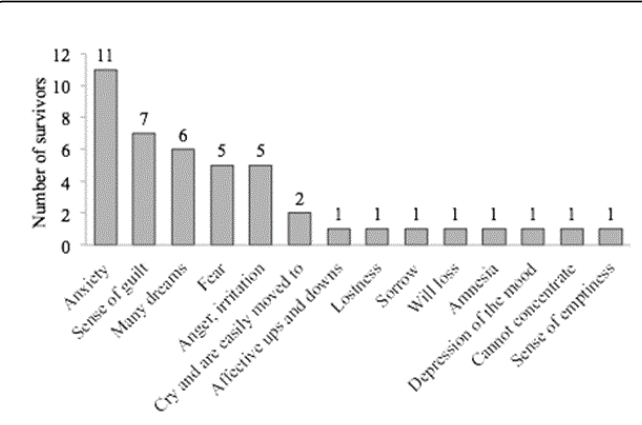

Figure 2B: Mental symptoms at first medical examination.

\section{Diagnosis according to the TEAM theories (TEAM syndromes)}

The most common TEAM syndromes were "liver qi stagnation" (43\%) and "depressed liver qi transforming into fire" (28\%) (Figure 3).

\section{Treatment with herbal medicines at the first examination}

Prescriptions for herbal medicine at the first medical examination were as follows: Kamishoyosan (Jia-wei-xiao-yao-san), 23 patients; Rikkunshito (Liu-jun-zi-shang), 5 patients; Keishibukuryogan (Guizhi-fu-ling-wan), 4 patients; Shoseiryuto (Xiao-qing-shang), 2 patients; Shin'iseihaito (Xin-yi-qing-fei-shang), 1 patient; Keigairengyoto (Jing-gai-lian-qiao-shang), 1 patient; and Rokumigan (Liu-wei-wan), 1 patient. Multiple herbal medicines were prescribed to patients, as needed.

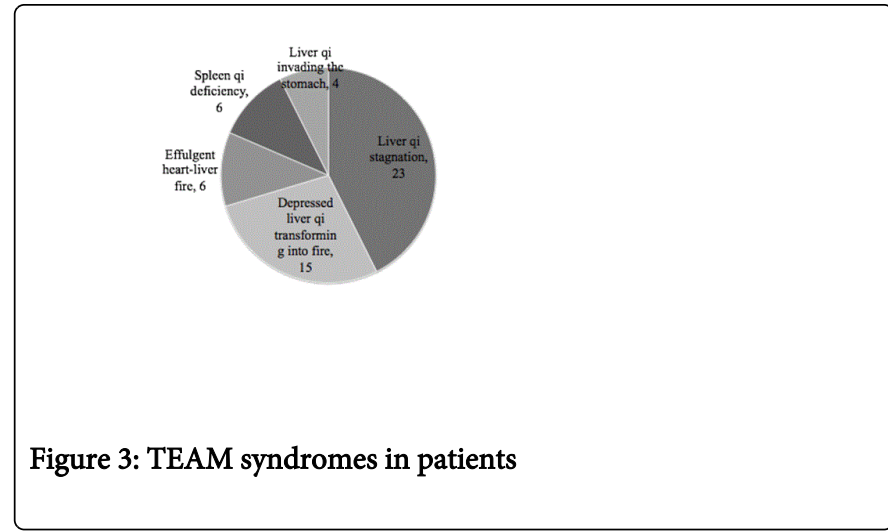

\section{The Impact of Event Scale - Revised Japanese-language version (IES-R-J)}

Twenty-three of the 32 patients participating in the study were considered appropriate to receive Kamishoyosan; 18 of the 23 patients who were prescribed Kamishoyosan completed the IES-R-J twice (before and after receiving the herbal prescription). Table 1 shows the IES-R-J patient scores including the total IES-R-J score, the sub-totals of the intrusion factor, the hyperarousal factor, and the avoidance factor. Most of the items showed significant improvement after the patients were prescribed Kamishoyosan, except for the following: "My feelings about it were kind of numb," "I found myself acting or feeling like I was back at that time," "I tried to remove it from my memory," and "I tried not to talk about it."

The first examinations and first IES-R-J assessments were performed between April and June 2011. The length of time between the first and second IES-R-J assessments was 4 to 6 months. Sixteen of the 18 patients showed improvement in their IES-R-J scores. However, the scores for 2 patients worsened-not only the total IES-R-J score but also the scores for all other items. It should be noted that these 2 patients had experienced terrible sights when the tsunami occurred. They saw some of the elderly residents of the nursing facility drown in front of them but were unable to help. For this, they were criticized by the bereaved family of the deceased elderly residents and were told, "My father died. Why are you living?"

\section{Adverse events}

There were no reports of adverse events associated with the use of the medicines.

\section{Discussion}

This study showed the potential effectiveness of the herbal medicine Kamishoyosan in improving the IES-R-J scores of tsunami survivors with stress-related disorders like PTSD at 1 to 2 months after the Great East Japan Earthquake.

\section{TEAM treatment for PTSD and syndromes in earthquake survivors}

Meng et al. used the herbal medicine Xiao-Tan-Jie-Yu-Fang to treat patients with PTSD after the 2008 earthquake in China. Xiao-Tan-JieYu-Fang was modified from a classic formula, Shoyosan (Xiao-YaoSan), the basic component of Kamishoyosan that we used on the earthquake survivors in Japan. Numata et al. used 
Citation: Seki T, Sasaki K, Mori S, Meguro K (2014) Use of Traditional East Asian Medicine to Diagnose and Kampo Medicine Kamishoyosan to Treat Survivors of the Great East Japan Earthquake 2011: A Retrospective Study. Altern Integr Med 3: 172. doi: $10.4172 / 2327-5162.1000172$

Page 4 of 7

Saikokeishikankyoto, which, like Kamishoyosan, is applied when there is "liver qi stagnation." TEAM syndromes in patients with PTSD, who were recruited by posting flyers or ads in the local media, were "liver qi stagnation," "heart shen disturbance"and"kidney deficiency" in another study [28].

\begin{tabular}{|c|c|c|c|c|c|c|c|c|c|}
\hline Subscale & Item & $\begin{array}{l}\text { Before } \\
\text { Mean } \pm \text { SD }\end{array}$ & $\begin{array}{l}\text { After } \\
\text { Mean } \quad \pm \\
\text { SD }\end{array}$ & $P$ value & Subscale & Item & $\begin{array}{l}\text { Before } \\
\text { Mean } \pm \text { SD }\end{array}$ & $\begin{array}{l}\text { After } \\
\text { Mean } \quad \pm \\
\text { SD }\end{array}$ & $P$ value \\
\hline Int & $\begin{array}{lr}\text { Any } & \text { reminder } \\
\text { brought } & \text { back } \\
\text { feelings about it }\end{array}$ & $2.5 \pm 1.1$ & $1.4 \pm 0.7$ & $<.0001$ & Avo & $\begin{array}{l}\text { I was aware that I still } \\
\text { had a lot of feelings } \\
\text { about it, but I dint deal } \\
\text { with them }\end{array}$ & $1.4 \pm 1.1$ & $0.7 \pm 0.6$ & 0.0008 \\
\hline Int & $\begin{array}{l}\text { I had trouble } \\
\text { staying asleep }\end{array}$ & $1.8 \pm 1.3$ & $0.9 \pm 0.9$ & 0.0028 & Avo & $\begin{array}{l}\text { My feelings about it } \\
\text { were numb }\end{array}$ & $1.2 \pm 1.2$ & $0.9 \pm 1.1$ & 0.1631 \\
\hline Int & $\begin{array}{l}\text { Other things kept } \\
\text { making me think } \\
\text { about it }\end{array}$ & $1.6 \pm 1.4$ & $0.7 \pm 0.7$ & 0.0009 & Int & $\begin{array}{l}\text { I found myself acting } \\
\text { about it were kind of } \\
\text { numb }\end{array}$ & $0.9 \pm 1.2$ & $0.6 \pm 0.8$ & 0.0827 \\
\hline Hyp & $\begin{array}{l}\text { I felt irritable and } \\
\text { angry }\end{array}$ & $1.3 \pm 1.0$ & $0.9 \pm 0.8$ & 0.007 & Нур & $\begin{array}{l}\text { I had trouble falling } \\
\text { asleep }\end{array}$ & $1.4 \pm 1.2$ & $0.7 \pm 0.8$ & 0.0043 \\
\hline Avo & $\begin{array}{l}\text { I avoided letting } \\
\text { myself get upset } \\
\text { when I thought } \\
\text { about it or was } \\
\text { reminded of it }\end{array}$ & $1.7 \pm 1.0$ & $0.9 \pm 0.6$ & 0.0007 & Int & $\begin{array}{l}\text { I had waves of strong } \\
\text { feeling about it }\end{array}$ & $2.1 \pm 1.0$ & $1.2 \pm 0.7$ & 0.0001 \\
\hline Int & $\begin{array}{l}\text { I thought about it } \\
\text { when I dint mean } \\
\text { to }\end{array}$ & $2.1 \pm 1.1$ & $1.3 \pm 0.7$ & 0.0134 & Avo & $\begin{array}{l}\text { I tried to remove it from } \\
\text { my memory }\end{array}$ & $0.8 \pm 0.9$ & $0.4 \pm 0.6$ & 0.069 \\
\hline Avo & $\begin{array}{l}\text { I felt as if it hadn't } \\
\text { happened or } \\
\text { wasn't real }\end{array}$ & $1.6 \pm 1.2$ & $0.9 \pm 0.9$ & 0.0229 & Нyp & 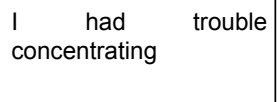 & $1.4 \pm 1.5$ & $0.8 \pm 1.2$ & 0.0079 \\
\hline Avo & $\begin{array}{l}\text { I stayed away } \\
\text { from reminders of } \\
\text { it }\end{array}$ & $1.6 \pm 1.1$ & $1.0 \pm 1.0$ & 0.0445 & Нyp & $\begin{array}{l}\text { Reminds of it caused } \\
\text { me to have physical } \\
\text { reactions, such as } \\
\text { sweating, trouble } \\
\text { breathing, nausea, or a } \\
\text { pounding heart }\end{array}$ & $1.4 \pm 1.2$ & $0.9 \pm 1.0$ & 0.0081 \\
\hline Int & $\begin{array}{l}\text { Pictures about it } \\
\text { popped into my } \\
\text { mind }\end{array}$ & $1.5 \pm 1.0$ & $0.8 \pm 0.8$ & 0.0018 & Int & I had dreams about it & $0.9 \pm 1.1$ & $0.4 \pm 0.6$ & 0.046 \\
\hline Hyp & $\begin{array}{l}\text { I was jumpy and } \\
\text { easily started }\end{array}$ & $1.8 \pm 1.3$ & $0.9 \pm 0.9$ & 0.009 & Нyр & $\begin{array}{l}\text { I felt watch full and on- } \\
\text { guard }\end{array}$ & $1.9 \pm 1.1$ & $1.2 \pm 0.9$ & 0.0018 \\
\hline Avo & $\begin{array}{l}\text { I tried not to think } \\
\text { about it }\end{array}$ & $1.3 \pm 1.1$ & $0.8 \pm 0.5$ & 0.0346 & Avo & $\begin{array}{l}\text { I tried not to think about } \\
\text { it }\end{array}$ & $0.8 \pm 0.8$ & $0.5 \pm 0.6$ & 0.0827 \\
\hline \multicolumn{7}{|c|}{ Instruction Factor (Subtotal) } & $14.6 \pm 7.1$ & $8.1 \pm 3.6$ & $<.0001$ \\
\hline \multicolumn{7}{|c|}{ Hyperarousal Factor (Subtotal) } & $11.3 \pm 6.0$ & $6.4 \pm 3.9$ & 0.0002 \\
\hline \multicolumn{7}{|c|}{ Avoidance Factor (Subtotal) } & $7.1 \pm 4.0$ & $4.2 \pm 3.0$ & 0.0008 \\
\hline \multicolumn{7}{|l|}{ Total } & $32.9 \pm 14.5$ & $18.8 \pm 7.9$ & $<.0001$ \\
\hline
\end{tabular}

Table 1: Scores of IES-R-J before and after prescription of Kamishoyosan.

In the present study, patients were diagnosed with TEAM and, where indicated, herbal medicines were prescribed. However, it was observed that all of the TEAM syndromes other than "liver qi stagnation" that were found in patients could have come from "liver qi stagnation," and the majority of patients (72\%) were diagnosed as having "liver qi stagnation," for which the herbal medicine
Kamishoyosan was indicated. It is known that the main cause of "liver qi stagnation" is mental stress. Thus, according to TEAM theories, it is reasonable to suggest that these patients were suffering from mental stress. The TEAM syndromes "depressed liver qi transforming into fire," "effulgent heart-liver fire"and "liver qi invading the stomach," 
Citation: Seki T, Sasaki K, Mori S, Meguro K (2014) Use of Traditional East Asian Medicine to Diagnose and Kampo Medicine Kamishoyosan to Treat Survivors of the Great East Japan Earthquake 2011: A Retrospective Study. Altern Integr Med 3: 172. doi: $10.4172 / 2327-5162.1000172$

Page 5 of 7

which some patients were suffering, can show as irritable conditions [29].

\section{Indication and mechanisms of action of Kamishoyosan}

Traditionally, Kamishoyosan has been used to treat a wide variety of mental and physical problems, including limb problems, heaviness of the head, dizziness, insomnia, irritability, burning sensation, menstrual abnormalities, and hot flashes [30], and has effects on mildto-moderate somatization disorders [31], women's general malaise and agitation [32], affective disorders [33,34], psychological stress insomnia [17], and depression [22,35].

In the IES-R-J scores of the study patients, it was found that three avoidance factor items- "My feelings about it were kind of numb," "I tried to remove it from my memory," and "I tried not to talk about it" - plus one intrusion factor item-"I found myself acting or feeling like I was back at that time"-did not change significantly after prescription of Kamishoyosan (Table 1). This may show the limitations of Kamishoyosan in treating PTSD-like stress.

Some of the major ingredients in Kamishoyosan are known to produce a sedative effect; they include the following: Angelicae Radix has a sedative effect in rabbits [36]; Paeoniae Radix has sedative and analgesic effects in mice [37]; Bupleuri Radix affects the central nervous system, causing sleep prolongation, sedation, and analgesia [38]; and Liquiritin, a flavone compound derived from Glycyrrhizae Radix, has shown an antidepressant effect in animal studies [39].

The psychological effects of Shoyosan, the basic component of Kamishoyosan, have also been reported; they include the following: antidepressant effect on rats in metabolomics study [40], amelioration of brain cortex 5-HT and 5-HIAA content in a mouse model of depression [41], regulation effect on the expression of AMPA receptors in chronic immobilization stress [42], upregulation of AMPA receptor subunit mRNA expression in the hippocampal region CA1 and amygdala [43], maintenance of the stability of hippocampal neurons [44], inhibition of hypothalamic-pituitary-adrenocortical axis negative feedback regulation [45], and counteraction on an increase in $\mathrm{Ca} 2+$ concentration in hippocampal synaptosomes [46].

\section{Situation of the study participants}

The patients who participated in the study were employees at the nursing facility for the elderly when it was hit by the tsunami. Thus, they were both rescue workers for the elderly at the facility and victims of the disaster. When the tsunami hit, their priority was to save the elderly residents of the nursing facility rather than focusing on their own need to escape and save themselves.

Most of the patients in the study lost their cars in the tsunami, and there was little gas available for those that still had cars. As a result, these patients did not have the opportunity to visit clinics for their own health. Moreover, because of the damage to transportation networks, hospitals, and the factory that produces Kampo medicine (Japanese herbal medicine), the availability of medical supplies in the disaster-stricken area was limited. OTC herbal medicines were supplied free by Kotaro Pharmaceutical Co., Ltd (Osaka, Japan). Authors visited the study facility as medical volunteers every weekend.

The earthquake and tsunami survivors suffered psychological as well as physical damage. The earthquake occurred on March 11, 2011, but from then until April 30, 2011, there were a total of 165 aftershocks with seismic intensity of 4 or more [47]. It was said that many of the survivors were affected psychologically, and 1 to 2 months after the disaster, many had become disillusioned [48]. Eleven of the 32 patients reported anxiety about the tsunami and aftershocks. Some of the patients with insomnia refused to take the soporific, because of the fear of another tsunami coming.

The victims of the Great East Japan Earthquake will need to receive ongoing care for physical and mental health issues for some time in the future. PTSD is associated with high healthcare costs [49]. Because herbal medicines are inexpensive and have few side effects, they are being used to treat many earthquake and tsunami victims in Japan. Furthermore, a matter of urgency is the predicted "Tokai Earthquake," a giant magnitude 8 earthquake with an epicenter inland of Shizuoka prefecture (near Tokyo), from the Gulf of Suruga [50].

Further investigation is warranted to explain the mechanisms of the use of the herbal medicine Kamishoyosan in the treatment of PTSD. The strategy of using an inexpensive herbal medicine to treat PTSD is worth studying.

\section{Limitations}

This retrospective study was limited by the fact that it included only a small number of participants (32) who survived the earthquake, and there were no controls. Second, because of the dynamics of the postearthquake situation, the authors were unable to have the study participants diagnosed by psychiatrists. Third, the herbal medicines that were given to the study participants were OTC products because of the limited medical conditions at the time; therefore, the quantity of herbal medicine prescribed may not have been sufficient to effect the desired results in some patients.

\section{Conclusion}

Survivors of the Great East Japan Earthquake who had limited access to medical care were diagnosed and treated according to TEAM theories and syndromes. More than $40 \%$ of the patients included in the study showed the TEAM syndrome "liver qi stagnation" 1 to 2 months after the disaster. They suffered not only stressful disorders like PTSD but also other TEAM syndromes caused by mental stress. The IES-R-J scores obtained for the patients showed improvement after administration of the herbal medicine Kamishoyosan to those for whom it was indicated by TEAM. However, the mental state of patients who had particularly violent or unpleasant experiences during or after the earthquake was exacerbated. The study suggested that the herbal medicine Kamishoyosan can be helpful in treating some stressful disorders like PTSD that result from disasters such as earthquakes.

\section{Acknowledgements}

The authors would like to thank Kotaro Pharmaceutical Co., Ltd, which provided herbal medicine to the earthquake survivors at no cost. We also wish to thank Ms. Hiroko Kobayashi (Tohoku University Hospital, Department of Laboratory Medicine), who supported our data collection efforts. We pray for the souls of the people who died in the Great East Japan Earthquake; may they rest in peace.

\section{References}

1. US Geological Survey Largest Earthquakes in the World Since 1900. In: U. S. Department of the Interior | U. S. Geological Survey, editor. 
Citation: Seki T, Sasaki K, Mori S, Meguro K (2014) Use of Traditional East Asian Medicine to Diagnose and Kampo Medicine Kamishoyosan to Treat Survivors of the Great East Japan Earthquake 2011: A Retrospective Study. Altern Integr Med 3: 172. doi: $10.4172 / 2327-5162.1000172$

Page 6 of 7

2. Neria Y, Nandi A, Galea S (2008) Post-traumatic stress disorder following disasters: a systematic review. Psychol Med 38: 467-480.

3. Kessler RC, Sonnega A, Bromet E, Hughes M, Nelson CB (1995) Posttraumatic stress disorder in the National Comorbidity Survey. Arch Gen Psychiatry 52: 1048-1060.

4. Wakabayashi Y (2003) Psychology of disaster and its fringe - a comunity approach fot stricken area by Hokkaido Nanseioki Earthquake. Tokyo

5. The Urgent Disaster Guard Head Quarters (2014) The damage situation and police action of the Tohoku district Pacific offing earthquake 2011. In: National Police Agency, editor. Tokyo.

6. Reconstruction Agency (2014) The number of refugees of the whole country. Tokyo.

7. NHK (2013) "Cannot have an actual feeling of the revival" $60 \%$ in 3 Tohoku prefectures. NHK NEWS WEB.

8. Fullerton CS, Ursano RJ, Wang L (2004) Acute stress disorder, posttraumatic stress disorder, and depression in disaster or rescue workers. Am J Psychiatry 161: 1370-1376.

9. Epstein RS, Fullerton CS, Ursano RJ (1998) Posttraumatic stress disorder following an air disaster: a prospective study. Am J Psychiatry 155: 934-938.

10. Kim Y (2011) Great East Japan earthquake and early mental-health-care response. Psychiatry Clin Neurosci 65: 539-548.

11. Meguro K (2011) Local response following the Great East Japan Earthquake 2011. Neurology 77: e12-15.

12. Satomi S (2011) The Great East Japan Earthquake: Tohoku University Hospital's efforts and lessons learned. Surg Today 41: 1171-1181.

13. Schoenfeld FB, Marmar CR, Neylan TC (2004) Current concepts in pharmacotherapy for posttraumatic stress disorder. Psychiatr Serv 55: 519-531.

14. Cukor J, Olden M, Lee F, Difede J (2010) Evidence-based treatments for PTSD, new directions, and special challenges. Ann N Y Acad Sci 1208: 82-89.

15. Foa EB, Franklin ME, Moser J (2002) Context in the clinic: how well do cognitive-behavioral therapies and medications work in combination? Biol Psychiatry 52: 987-997.

16. Hoizey D, Hoizey M-J (1993) A History of Chinese Medicine. Bailey P translator. Edinburgh: Edinburgh University Press.

17. Li Y, Xu BY, Xiao F (2009) Effect of modified xiaoyao powder for improving sleep in patients with psychological stress insomnia. Chinese journal of integrated traditional and Western medicine 29: 208-211.

18. Yu HT (2006) Clinical observation on treatment of somatic disorder with combination of Xiaoyao Powder and Wendan Decoction. Chinese journal of integrated traditional and Western medicine 26: 1114-1116.

19. Yi ZH, Zhu LP, Long B (2010) Clinical observation on treatment of major depressive disorder by paroxetine combined with chaihu xiaoyao mixture. Chinese journal of integrated traditional and Western medicine 30: 1257-1260.

20. Yang ZY, Zhang WB, Liu JL (2007) Comparative study of Modified Xiaoyao Pill combining amitriptyline on therapeutic effect and compliance in treating patients with depression. Chinese journal of integrated traditional and Western medicine 27: 642-644.

21. Yu GH, Liang SC, Sun QZ (2007) Study on Modified Xiaoyao Decoction combining Clomipramine treating depression. Chinese journal of integrated traditional and Western medicine 27: 318-320.

22. Luo HC, Qian RQ, Zhao XY, Bi J, Xin H, et al. (2006) Clinica observation on effect of danzhi xiaoyao powder in treating depression. Chinese journal of integrated traditional and Western medicine 26: 212-214.

23. Qian LQ, Wang B, Niu JY, Gao S, Zhao DY (2010) Assessment of the clinical effect of Chinese medicine therapy combined with psychological intervention for treatment of patients of peri-menopausal syndrome complicated with hyperlipidemia. Chin J Integr Med 16: 124-130.

24. Meng XZ, Wu F, Wei PK, Xiu LJ, Shi J, et al. (2012) A chinese herbal formula to improve general psychological status in posttraumatic stress disorder: a randomized placebo-controlled trial on sichuan earthquake survivors. Evid Based Complement Alternat Med 2012: 691258.

25. Asukai N, Kato H, Kawamura N, Kim Y, Yamamoto K, et al (2002) Reliability and validity of the Japanese-language version of the Impact of Event Scale-Revised(IES-R-J);Four studies on different traumatic events. J Nerv Ment Dis: 175-182.

26. Horowitz M, Wilner N, Alvarez W (1979) Impact of Event Scale: a measure of subjective stress. Psychosom Med 41: 209-218.

27. Weiss DS, Marmar CR, Wilson J, Keane T, et al (1997) The impact of event scale-revised. In: Assessing psychoogical trauma and PTSD. New York The Guilford Press Pp 399-411.

28. Hollifield M, Sinclair-Lian N, Warner TD, Hammerschlag R (2007) Acupuncture for posttraumatic stress disorder: a randomized controlled pilot trial. J Nerv Ment Dis 195: 504-513.

29. Liu G, Hyodo A (2006) Fundamentals of acupuncture \& moxibustion. Huaxia publishing house Beijing

30. Otuka K, Yakazu D, Shimizu T (2001) Kanpo Shinryo Iten: Nanzando Co Ltd

31. Yamada K (2003) Application of the Kami-shoyo-san in neuropsychiatry. Kanpo to Saisin Chiryou 12: 57-60.

32. Morita H, Arita M, Ishida S, Ozaki T (1997) Kami-shoyo-san's autonomic nervous function and effects on mind and body symptoms. Kanpo Igaku 21: 177-179.

33. Zhang LD, Zhang YL, Xu SH, Zhou G, Jin SB (1994) Traditional Chinese medicine typing of affective disorders and treatment. Am J Chin Med 22: 321-327.

34. Oka $\mathrm{T}$ (2003) Effect of Kami-shoyo-san on antistress and stress associated diseases. Kanpo to saisin chiryo 12: 66-68.

35. Xu ZW, Wu LL, Ya VC (2003) The experimental research on antidepression effects of xiaoyaosan decoction and danzhi xiaoyaosan decoction. Acta Chinese Medicine and Pharmacology 31: 61.

36. Saeki T (1965) Basic study on mechanism of action for the rabbit ocular tension of Angelicae Radix-effects for the blood pressure. Rinsyo Ganka 19: 647-654.

37. Takagi K, Harada M (1969) Pharmacological Studies on Herb Paeony Root. I. : Central Effects of Paeoniflorin and Combined Effects with Licorice Component FM 100. Yakugaku Zasshi 89: 879-886.

38. Takagi K, Shibata T (1969) Pharmacological Studies on Bupleurum falcatum L.I. : Acute Toxicity and Central Depressant Action of Crude Saikosides. Yakugaku Zasshi 89: 712-720.

39. Zhao Z, Wang W, Guo H, Zhou D (2008) Antidepressant-like effect of liquiritin from Glycyrrhiza uralensis in chronic variable stress induced depression model rats. Behav Brain Res 194: 108-113.

40. Dai Y, Li Z, Xue L, Dou C, Zhou Y, et al. (2010) Metabolomics study on the anti-depression effect of xiaoyaosan on rat model of chronic unpredictable mild stress. J Ethnopharmacol 128: 482-489.

41. Bao L, Chen J, Huang L, Chen W, Lin Q, et al. (2008) Effects of Xiaoyao Wan on the behavioral despair and stress depression mice. Journal of Chinese medicinal materials 31: 1360-1364

42. Yue GX, Wang ZF, Zhang QL, Zhao X, Yue LF, et al. (2008) Expression of AMPA receptors and related protein in immobilization stressed rats and effect of Xiaoyaosan. Chinese journal of applied physiology 24: 129-132.

43. Yue GX, Wang ZF, Zhang QL (2007) Changes of central AMPA receptor subunits and related protein mRNA expression in immobilization stressed rats and effect of Xiaoyaosan on them. Chinese journal of integrated traditional and Western medicine 27: 1110-1115

44. Xu ZW, Sun Q, Ao HQ, Wang WZ, Fu WJ (2011) Effects of Xiaoyao powder on NR1, NR2A and NR2B mRNA expression in cultured hippocampal neurons of rats under chronic stress. Journal of Guangzhou University of Traditional Chinese Medicine 28: 36-42.

45. Xu ZW, Fu WJ, Ao HQ (2009) Effect of Xiaoyaosan on HPA axis negative feedback regulation function of rats with chronic stress. Journal of Shanxi College of Traditional Chinese Medicine 10: 15-17. 
Citation: Seki T, Sasaki K, Mori S, Meguro K (2014) Use of Traditional East Asian Medicine to Diagnose and Kampo Medicine Kamishoyosan to Treat Survivors of the Great East Japan Earthquake 2011: A Retrospective Study. Altern Integr Med 3: 172. doi: $10.4172 / 2327-5162.1000172$

Page 7 of 7

46. Xu ZW, Ao HQ, Yan C, Wu LL, Wang WZ (2005) Effect of Xiaoyao powder on $\mathrm{Ca} 2+$ in hippocampal synaptosome of Multi-stress model rats. Journal of Guangzhou University of Traditional Chinese Medicine 22: 42-45.

47. Department of Earthquake and Volcano (2014) Number of earthquakes of Tohoku district Pacific offing earthquake 2011: maximal seismic intensity 4 or more. In: Japan Meteorological Agency Tokyo.
48. Romo D (1995) Handbook of disaster and psychological care: ASK human care inc.

49. Walker EA, Katon W, Russo J, Ciechanowski P, Newman E, et al. (2003) Health care costs associated with posttraumatic stress disorder symptoms in women. Arch Gen Psychiatry 60: 369-374.

50. Japan Meteorological Agency (2014) Urgency of occurrence of Tokai Earthquake. In: Ministry of Land Infrastructure and Transport 